\title{
TRANSFORMATIVE LEADERSHIP IN MULTICULTURAL SCHOOLING CONTEXTS: A CRITICAL REFLECTION OF IN-SERVICE TEACHERS' PRACTICES AND SCHOOL MANAGERS' ROLES
}

\author{
Rantsie Kgothule ${ }^{1}$, June Palmer ${ }^{2}$, Gregg Alexander ${ }^{2}$, \& Edwin De Klerk ${ }^{3}$ \\ ${ }^{1}$ School of Education Studies, University of the Free State (South Africa) \\ ${ }^{2}$ Department Postgraduate Studies in Education, Central University of Technology (South Africa) \\ ${ }^{3}$ School of Education Studies, Sol Plaatje University (South Africa)
}

\begin{abstract}
In exercising their power and authority, School Management Teams (SMTs) should engage in transformative leadership which commences with interrogations regarding social justice, democracy and social responsibility. According to Freire's philosophy of education it is further expected of SMT members to support and shape the belief that autonomy is a condition arising from the responsible engagement with decision-making; that we are 'unfinished' in our development as human beings; and that we are responsible for the development of a critical consciousness as a necessary condition of freedom and the creation of democratic and equitable learning spaces. In a transformative leadership context, authority must inform all critical practices of pedagogical intervention and goal setting should support in-service teacher's autonomy, self-worth and develop their potential and the level of intrinsic motivation to flourish in inclusive school settings. This paper reports on a qualitative pilot study conducted with SMT members and teachers in the Northern Cape Province of South Africa to gain their insights regarding their roles as leaders in devising mechanisms to invest in radical democratic principles and the promotion of inclusive school practices. The key findings indicate that the SMT's role require that they interrogate their frame of reference and transform their thinking in terms of social justice in multicultural school settings and create opportunities for in-service teachers to develop professionally and use digital technology creatively to enhance teaching and learning. As a force for transformation, we conclude that transformative leadership may be a catalyst to engage school leaders and teachers in individual and combined processes of awareness of inclusive practices and action.
\end{abstract}

Keywords: Transformative leadership, school management teams, autonomy, inclusive practices.

\section{Introduction}

Multicultural education provides teachers and SMTs with opportunities to work with different school populaces and attain justice within societies discernible by disparities based on ethnicity, language, religion, gender and socioeconomic status (Banks, 2004). Teachers and SMTs should actively integrate programmes which would speak to diversity to assist learners to improve their academic performance and promote their overall development as human beings (Pourdavood \& Yan, 2020). Transformative leadership may be a pathway to change outcomes for learners in multicultural school settings (Shields \& Warke, 2010; Theoharis, 2007).

Transformative leadership requires that action be taken to redress inequalities and to guarantee that learners have equal opportunities to develop optimally, to be treated with dignity and to improve their competences (Shields, 2014). Inequities unfavorably impact on the learning and success of learners (Shields \& Warke, 2010) and calls for inclusive practices to be applied to learning by advocating for traditionally marginalized learners. Inclusive Education was a focal point during the approval of the 1994 Salamanca statement at the World Conference on Special Needs Education: Access and Quality, organized by UNESCO in Spain. The conference formally approved inclusive education as the furthermost active way of ensuring that everybody enjoys equal education opportunities (UNESCO, 1994). As socially just agents, transformative leaders ought to proactively and meticulously contest the political and social issues that perpetuate inequities in schools (Skrla, McKenzie, \& Sheurich, 2009). This study, therefore, poses the question: What are the roles of SMT members and teachers in devising mechanisms to institute radical democratic principles to promote inclusive school practices? 


\section{Literature review}

\subsection{Transformative leadership as catalyst for transforming multicultural schools}

Multicultural schools are representative of opinions and behaviors that respect and acknowledge the existence of different groups in society, recognizes and values their socio-cultural dissimilarities, and encourage and allow for a continual involvement within an inclusive cultural setting (Rosado, 2020).

Transformative leadership (TL) seems to be ideal in terms of teachers' practices and principals' roles in leading schools in multicultural contexts. Montuori and Donnely (2018) assert that transformative leadership invites individuals to take responsibility in asking what kind of world they would like to create through their interactions, opinions and beliefs, and link it to the ideal school environment. This implies that TL may be regarded as driving force which should inspire individuals to be more creative, interconnected and more personal - principles that embody individuals' desired ideals and allow them to make an influence that mirrors their ethics, expectations, and anxieties (Montuori, 2010). Consequently, TL steers attention to leadership in multicultural contexts in that it may assist teachers and principals to make positive contributions to development in schools (Vora et al., 2018).

\subsection{Developing teacher autonomy and inclusive learning spaces}

As transformative leaders, the role the senior management teams (SMTs) in schools should be develop teacher autonomy and create inclusive teaching and learning spaces as ways to lead in multicultural school contexts. In so doing, SMTs should foster the development of autonomous, socially answerable and critical conscious individuals, "within a vision of education as (inter)personal empowerment and social transformation" (Vieira, 2006, 23 as cited in De Klerk, 2014, 195). Teacher autonomy should prepare in-service teachers to independently and disparagingly reflect on the privileges and power of prevailing cultures, their individual space within schools, and to analyze issues of multiculturalism to construct equal and inclusive learning spaces through their teaching practice (Alismail, 2016).

One way in developing inclusive learning spaces is to foster numerous opportunities for engagement, that is, providing flexible and diverse platforms for distinct learning, teamwork and collaboration (Holeton, 2020). An inclusive, learning-friendly classroom (ILFC) invites, encourages, and teaches all learners irrespective of their linguistic, intellectual, gender, emotional or social characteristics. An ILFC is, therefore, a space in which teachers understand the significance of diversity and plans such that all learners are treated similarly (Salahuddin, 2017).

\subsection{Promoting inclusive practices for transformative leadership professional development}

To promote inclusive practices, Education White Paper 6 highlights that professional development should be based on, "the development of effective leadership in policy, administration and programme implementation, the establishment of management information systems, and the development of competencies" (Republic of South Africa [RSA], 2001, 28). Interpreting the stipulation in RSA (2001), the intention of inclusive practices for transformative leadership professional development should be aimed at improving the skills, attitudes, understanding and performance of teachers [and SMTs] in terms of understanding key strategies critical to achieving success (Salahuddin, 2017).

Inclusive practices for transformative leadership professional development are needed to support an inclusive environment in multicultural school contexts in which diverse team members are respected for their efforts to ensure a sense of belonging and appreciation for distinctiveness (Ashikali, Groeneveld $\&$ Kuipers, 2020).

\section{Theoretical Framework}

This paper explores in-service teachers' practices and school managers' roles in multicultural schooling contexts through the lens of transformative leadership theory (TLT) (Shields, 2011; 2016). This theory critiques practices by offering greater individual achievement as well as "a better life in common with others" (Shields, 2011, 5). TLT is beneficial all stakeholders, with attention paid to issues of academic attainment, language, culture, beliefs and gender (Theoharis, 2007 as cited in Shields \& Hesbol, 2020). Consistent with TLT, the afore-mentioned issues have relevance to multicultural schooling contexts in that it requires transformative leaders to make calculated and informed decisions, take risks and manage multiculturalism, whilst displaying a sense of culture and accountability (Shields, 2011).

We were aware that the application of TLT (Shields, 2011, 2016) requires that we should be cognizant of possible risks of analyzing data in such a way that it would affect the explanation thereof (Evers \& Wu, 2006). Having said this, we were deliberate to prudently ground the data in a practical inferential system (Evers \& Wu, 2006) focusing on teachers' practices and school managers' roles in multicultural school contexts. 


\section{Methodology}

\subsection{Setting and participants}

The data for this pilot study was collected from an ex-model C multicultural Afrikaans public primary school with 324 learners from Grades $\mathrm{R}$ to 7 with 08 teachers and 05 assistant teachers. The assistant teachers perform duties from Gr R-4, and the school is situated in a rural area in the Northern Cape Province of South Africa. Participants included two teachers, one head of department and the principal of the school. The principal, HoDs and teachers received an introductory email before we started with the process of data collection, providing information about the study. We requested that they complete the interview document through email. The email comprised information about privacy, start and end dates, as well as a link to the semi-structured interview schedule. The participants expressed their willingness to be part of the research study as they believed that it would benefit them because involvements of this kind may encourage development within the school. Participants completed the interview schedules electronically and emailed it back to the researchers. The analysis of the data focused on the answers provided in the interview schedule and the content of the participants' responses in line with the research question.

\subsection{Qualitative pilot study}

Qualitative pilot studies used in research are reduced forms of larger studies, also referred to as viability studies, and the pre-testing of a specific research tool (Baker, 1994). The pilot study is used to evaluate the feasibilities of the main study in respect of its application as well as usefulness and frequently contains an evaluation of resources, such as costs and time, for the main study (Gudmundsdottir \& Brock-Utne, 2010). Our pilot study aims to yield practical information about the main study to be conducted and to gain participants' insights regarding their roles as transformative leaders in devising mechanisms to invest in radical democratic principles and the promotion of inclusive school practices in multicultural schools.

\section{Discussion}

The discussion will be based on reviewing the research findings, showing how it relates to the literature review as well as our research question. The school will be referred to as School A, teachers as $\mathrm{T} 1$ and $\mathrm{T} 2$, the head of department as HoD and the principal as P1.

We started the interview by asking the question: How is learner inclusivity addressed in your school? A teacher responded thus: I can say that we really include them in everything that we do. And it was good to strengthen issues regarding differentiation. In this regard, we gave activities in line with the cognitive abilities of our learners and even provided opportunities for re-assessment where necessary [T1]. When probed to provide some of the corrective and supportive strategies teachers have put in place to assist learners in their learning to promote individual progress, behaviour, and social-emotional development during the COVID-19 pandemic, a teacher indicated: Learners who struggled were given opportunities to redo activities. I also sent motivational messages to parents via WhatsApp to encourage learners when they must complete activities. The parents appreciated this [T2]. Salahuddin (2017) agrees that to ensure the success of inclusive practices and build a country's social capital, individuals such as parents and teachers as well as communities must work together.

Teachers further elaborated on the platforms that are created for learners to identify and challenge injustices, express their feelings about how to improve their learning experiences within the school by indicating: I requested parents to allow their children to send me messages on their WhatsApp. This worked quite well and I experienced that communicating with them made them feel good. I also had a WhatsApp group with parents and many a times I read messages where parents give guidance to other parents and how they motivate each other [T2].

Upon probing the participants about the leadership style of the SMT and the creation of developmental opportunities for teachers to show leadership they mentioned: We had regular updates from the SMT on our staff's WhatsApp group. They would alert us about teaching and learning programmes on the radio and television. They also held regular Zoom meetings with us and we received emails. They used these platforms to keep us in the loop regarding educational developments [T1]. Teachers are encouraged to attend departmental workshops and courses and partake in virtual training [T2]. The teachers reported receiving a lot of support and professional inspiration from their leaders who encourage them to lead and innovate in their classrooms while contributing to the development of their colleagues and the school. When teachers are enabled to be autonomous and can take a leadership role themselves, they acquire professional confidence that fosters effective teaching practice (De Klerk, 2014; Wayne \& Youngs, 2003). 
SMT members were probed on some of the issues and challenges that COVID-19 has brought and the types of inequalities that the pandemic has highlighted in the school. Due to anxiety and stress, some parents withdrew their learners from school and some of the learners only attended school when they wished to do so. It was difficult for learners to follow teaching and learning programmes because most of them do not have a television or even a computer at home. I mean, technology and the use thereof are a huge problem within our community [P1]. Determining exactly how much the COVID-19 pandemic has impacted on curriculum delivery, may be difficult and an accurate assessment may only be made once teachers and learners return to schools and the extent to which the gap between disadvantaged children and their peers has changed. Although schools' closings have undoubtedly contributed to slow the spread of COVID-19, the use of virtual education platforms, as a substitute for face-to-face classes, is challenging and firstly impact learners from disadvantaged backgrounds (Teymori \& Fardin, 2020).

To the question on how learning support is offered to learners with disabilities and online teaching strategies, an SMT member responded in the following way: This was difficult and we could only provide parents with necessary material to ensure that some of teaching and learning would take place at home. We decided to only assess learners in terms of work already completed in order not to burden them with unfamiliar things. This really help and ensured that learners progress at a good pace, we are very aware of the fact that many learners struggle academically [HoD]. We provided learners with containing learning activities which were collected after completion [P1]. Significantly, transformative leaders promote an inclusive vision by eliciting, "elicit high performance because they strongly believe in the abilities of their constituents" (Kouzes \& Posner, 2012, 276). This conviction (Kouzes \& Posner, 2012), when combined with leadership resources and support, validates trust that transformative leaders have in their teachers and senior management team members, and builds collegial trust in return.

SMT members were probed on how their leadership assisted in the execution of actions to promote teaching and learning to mitigate COVID-19 and inclusiveness in the school. The principal indicated: I allowed teachers to work independently, ensure that they would feel in charge of their own teaching practices. I also developed a reporting template on which they would provide information about learners' progress and completion of activities. They understood that the idea was not to check on them, but that mechanisms were put in place to ensure that all learners got equal opportunities to learn [P1]. Transformative leaders thus stimulate innovative personal qualities, strengthening individuals' creativity, unlock intellectual abilities and encourage participative leadership (Abdelrahman \& Kelly, 2019).

The current pandemic offers unprecedented challenges, but also opportunities: although the usual way of teaching, learning and school leadership have been disturbed, spaces have been created to reimagine instruction approaches as well as leadership abilities.

\section{Conclusion}

This pilot study was conducted to acquire knowledge regarding transformative leadership in multicultural schooling contexts. The responses from participants (teaches and SMT members) revealed that the development of inclusive learning spaces is imperative in transforming, motivating and enhancing diverse platforms for learner development. Successful inclusion practices not only accentuate the significance of leaners in the classroom, but it also highlights the quality of their experiences and their academic attainment in terms of curriculum content. Teachers and SMT members play a fundamental role in ensuring that inclusive practices are regarded as fundamental in education. Based on the findings the pilot study yielded, we were able to adapt our interview schedules and improve the research design which will inform the larger study we are undertaking.

\section{References}

Abdelrahman, Z., \& Kelly. L. (2019). The role of CEO transformational leadership and innovation climate in exploration and exploitation. European Journal of Innovation Management, 22, 84-104.

Alismail, H.A. (2016). Multicultural Education: Teachers' Perceptions and Preparation. Journal of Education and Practice, 7(11), 139-146.

Ashikali, T., Groeneveld, S., \& Kuipers, B. (2020). The Role of Inclusive Leadership in Supporting an Inclusive Climate in Diverse Public Sector Teams. Review of Public Personnel Administration, 2020, 1-23.

Baker, T.L. (1994). Doing social research (2nd ed.). New York, NY: McGraw-Hill.

Banks, J.A. (2004). Teaching for social justice, diversity, and citizenship in a global world. In The Educational Forum, 68(4), 296-305. 
Bennis, W., \& Nanus, B. (2007). Leaders: Strategies for Taking Charge. 2nd Edition. New York, NY: Harper-Collins.

De Klerk, E.D. (2014). Teacher autonomy and professionalism: A policy archaeology perspective. M.Ed.-dissertation. Bloemfontein: University of the Free State.

Evers, C.W., \& Wu, E.H. (2006). On generalising from single case studies: Epistemological reflections. Journal of Philosophy of Education, 40, 511-526.

Gudmundsdottir, G.B., \& Brock-Utne, B. (2010). An exploration of the importance of piloting and access as action research. Educational Action Research, 18, 359-372.

Holeton, R. (2020). Toward Inclusive Learning Spaces: Physiological, Cognitive, and Cultural Inclusion and the Learning Space Rating System. Retrieved February March 17, 2021, from: https://er.educause.edu/articles/2020/2/toward-inclusive-learning-spaces

Kouzes, J., \& Posner, B. (2012). The Leadership Challenge (5th ed.). San Francisco, CA: Jossey Bass.

Montuori, A. (2010). Transformative leadership for the 21st century. Reflections on the design of a graduate leadership curriculum. ReVision, 30(3-4), 4-14.

Montuori, A., \& Donnely, G. (2018). Transformative Leadership. In J Neal (ed.). Handbook of Personal and Organizational Transformation (pp. 1-32). San Francisco, CA, USA: Springer International Publishing.

Pourdavood, R.G., \& Yan, M. (2020). Becoming Critical: In-service Teachers' Perspectives on Multicultural Education. International Journal of Learning, Teaching and Educational Research, 19(2), 112-135.

Republic of South Africa. (2001). Education White Paper 6. Building an Inclusive Education and Training System. Pretoria: Government Printer.

Rosado, C. (2020). What makes a school multicultural? Retrieved February March 17, 2021, from: http://www.edchange.org/multicultural/papers/caleb/multicultural.html

Salahuddin, S.F. (2017). Building inclusive learning friendly classrooms: need of the hour. International Journal of Reflective Research in Social Sciences, 1(1), 10-13.

Shields, C.M. (2011). Transformative leadership: An introduction. In C.M. Shields (Ed.), Transformative Leadership: A Reader (pp. 1-17). New York, USA: Peter Lang.

Shields, C.M. (2014). "Ethical leadership: a critical transformative approach". In C.M. Branson C.M. \& S.J. Gross (Eds.), Handbook of Ethical Educational Leadership (pp. 24-43). New York, NY: Routledge.

Shields, C.M. (2016). Transformative leadership in education: Equitable and socially just change in an uncertain and complex world (2nd ed.). New York, NY: Routledge.

Shields, C.M., \& Hesbol, K.A. (2020). Transformative Leadership Approaches to Inclusion, Equity, and Social Justice. Journal of School Leadership, 30(1), 3-22.

Shields, C.M., \& Warke, A. (2010). "The invisible crisis: connecting schools with homeless families". Journal of School Leadership, 20(6), 789-819.

Skrla, L.E., McKenzie, K., \& Sheurich, J.J. (Eds). (2009) Using equity audits to create equitable and excellent schools. Thousand Oaks, CA: Corwin Press.

Teymori, A.N. \& Fardin, M.A. 2020. COVID-19 and Educational Challenges: A Review of the Benefits of Online Education. Ann Mil Health Sci Res. (In Press): e105778

Theoharis, G. (2007). Social justice educational leaders and resistance: toward a theory of social justice leadership. Educational Administration Quarterly, 43(2), 221-258.

UNESCO. (1994). The Salamanca Statement and Framework for Action on Special Needs Education. Adopted by the World Conference on Special Needs Education: Access and Quality. Salamanca, Spain: UNESCO.

Vora, D., Martin, L., Fitzsimmons, A.R., Pekerti, A.A., Lakshman, C., \& Raheem, S. (2018). Multiculturalism within individuals: A review, critique, and agenda for future research. Journal of International Business Studies, 50(6), 1-26.

Wayne, A. \& Youngs, P. (2003). Teacher characteristics and student achievement gains: A review. Review of Educational Research, 73(1), 89-122 